\section{Using clinically stable disease (NEDA 2) as a proxy for disease impact and employment in MS paints an incomplete picture}

\author{
Sharon Roman
}

\section{Obstacles to employment are multi-factorial and can extend beyond disease activity in MS}

Multiple sclerosis (MS) has long been associated with high rates of unemployment. ${ }^{1}$ While in many countries, patients are entitled to ask for reasonable accommodations, ${ }^{2}$ the duty to accommodate still operates within the confines of being able to fulfil the job requirements. Fluctuations in disease and pseudo exacerbations can confound meeting these requirements, making permanent and meaningful employment out of reach for many, as most people with MS are not free of all disease activity. ${ }^{3}$ Obstacles to employment are multifactorial and can be independent of clinically stable disease, a measurement used in the paper by Ameriet al. ${ }^{4}$

Alone in an empty room, all I could do was laugh uncontrollably-at nothing at all. My outbursts of laughter had punctuated the meeting; answering questions with a recalcitrant tongue made Ls and Ns difficult. Leaning against a wall for support, all I wanted to do was sleep. The symptoms of MS were becoming too great to ignore. I struggled with a constellation of symptoms; fatigue, dysarthria, balance, intention tremor, ataxia and now the pseudobulbar affect. Little did I know that it was much more than an embarrassing, costly annoyance that stood in the way of a business deal that day, threatening my livelihood. Further disease activity produced diplopia (vertical), bladder dysfunction, Uhtoff's phenomenon and more; fluorescent lights, so common in

Correspondence to Sharon Roman, Vancouver, British Columbia, Canada; slhroman@gmail.com the workplace, can trigger my symptoms and side effects of medications can add to the burden of disease. Non-radiographic or transient symptoms may be difficult to measure in clinic, yet can be life-altering and should be included when measuring disease impact.

More relevant to job fulfilment and social functioning than the composite scoring system of the Expanded Disability Status Scale (EDSS) is the fact that disability is multidimensional and includes invisible symptoms. The nature of the impairment and its impact on daily living must be weighed in its entirety to form a more salient prognostic indicator of MS and employment. Pathology can differ from impairment, and although the link between pathological process and impairment is relatively close and invaluable in making a diagnosis, it is not absolute. $^{5}$

An optimal MS clinical outcome measure should be multidimensional to reflect the principal ways MS affects an individual-leg function and ambulation; arm and hand function; cognitive function; visual function; sensory function; and bowel and bladder. ${ }^{6}$ Extending symptom measurement, the Multiple Sclerosis Functional Composite (MSFC) emerged as the most robust predictor of employment status in MS patients, exceeding the predictive value of the EDSS. ${ }^{7}$ While subjective, to better reflect the myriad ways MS changes lives, the addition of patient-reported impacts of disease also needs consideration.
We can, and should, go farther when measuring disability to reflect the true impact of MS. The threat of financial helplessness and becoming an economic burden is no laughing matter.

Funding This research has received no specific grant from any funding agency in the public, commercial or not-for-profit sectors.

Competing interests None declared.

Patient consent for publication Not required.

Provenance and peer review Commissioned; internally peer reviewed.

(c) Author(s) (or their employer(s)) 2020. No commercial re-use. See rights and permissions. Published by BMJ.

Check for updates

To cite Roman S. J Neurol Neurosurg Psychiatry 2020;91:5.

Received 9 September 2019

Accepted 14 September 2019

Published Online First 14 November 2019

\section{Linked}

http://dx.doi.org/10.1136/jnnp-2019-321523

J Neurol Neurosurg Psychiatry 2020;91:5.

doi:10.1136/jnnp-2019-321778

\section{REFERENCES}

1. Julian LJ, Vella L, Vollmer T, et al. Employment in multiple sclerosis. exiting and re-entering the work force.. J Neurol 2008;255:1354.

2. MS in the Workplace: An employer's guide. MS Society of Canada.

3. Rae-Grant A, Day GS, Marrie RA, et al. Practice guideline recommendations summary: diseasemodifying therapies for adults with multiple sclerosis: report of the Guideline development, Dissemination, and Implementation Subcommittee of the American Academy of Neurology. Neurology 2018;90:777-88.

4. Ameri CT, Mathias B, Zsolt I, et al. Clinically stable disease is associated with a lower risk of both income loss and disability pension for patients with multiple sclerosis. "N Neurol Neurosurg Psychiatry 2020;91:67-74.

5. Wade DT. Epidemiology of disabling neurological disease: how and why does disability occur? Journal of Neurology, Neurosurgery \& Psychiatry 1997;63(Supplement 1):11S-18.

6. Fischer Jill S, Jak Amy J, Kniker Judith E. Multiple sclerosis functional composite (MSFC) administration and scoring manual. 1, 2001.

7. Honarmand K, Akbar N, Kou N, et al. Predicting employment status in multiple sclerosis patients: the utility of the MS functional composite. J Neurol 2011;258:244-9. Feb. 